\title{
Panorama de las Pyme del Sector turístico EN COLOMBIA EN EL MARCO DE LA ALIANZA DEL PACIFICO*
}

\author{
OVERVIEW OF SME'S IN THE TOURISM SECTOR IN COLOMBIA WITHIN THE \\ FRAMEWORK OF THE PACIFIC ALLIANCE
}

Fernando Chavarro Miranda**

Alexander Sellamén Garzón*****

Recibido: 28 de junio de 2016

Aceptado: 25 de abril de 2017

\section{Resumen}

El documento presenta una perspectiva de las PyME del sector turismo en Colombia en el marco de la Alianza del Pacífico, a partir del análisis y el diagnóstico de la competitividad de las PyME colombianas. Para esto, se realiza el respectivo estudio con base en datos estadísticos proporcionados por distintas entidades, a partir de lo cual se ejecuta una descripción general de la situación de las PyME del sector turístico de Colombia frente a la dinámica sectorial en México, Perú y Chile. Se definen cuáles son las actividades que más proporcionan o establecen un mayor aporte al sector, las principales nacionalidades de los turistas que ingresan a cada país, entre otros aspectos, y se realiza una balance de la situación del sector turístico colombiano respecto a los demás países, evaluando con ello puntos débiles y fortalezas que tiene este sector de la economía nacional.

Palabras clave: PyME, competitividad, acuerdos internacionales.

\section{Abstract}

The paper presents a perspective of SMEs in the tourism sector in Colombia as part of the Pacific Alliance (AP) from the analysis and diagnosis of the competitiveness of Colombian SMEs. For this, the respective study is done based on statistical data provided by different entities, from which an overview of the situation of SMEs in the tourism sector of Colombia against sectoral dynamics in Mexico, Peru and Chile runs. We analyze which activities register a greater contribution to the sector, the main nationalities of tourists entering each country, among other things. Finally, a stocktaking of the Colombian tourism sector is made as to the other countries in question, thereby evaluating weaknesses and strengths that has the sector of the national economy.

Keywords: SMEs, Competitiveness, International Agreements.

\footnotetext{
*Artículo de investigación derivado de la línea de investigación en Integración Económica de la Facultad de Educación Permanente y Avanzada de la Fundación Universidad de América. Este documento fue elaborado con el apoyo de Edna Yicel Corredor Retis, estudiante del programa de economía.

${ }^{* *}$ Economista, docente investigador, grupo de investigación Gestión y Competitividad de las Organizaciones, Fundación Universidad de América. fchavarr@uniandino.com.co

*** Economista, docente investigador, grupo de investigación Gestión y Competitividad de las Organizaciones, Fundación Universidad de América. alexsellamen@gmail.com
} 


\section{INTRODUCCIÓN}

Las PyME en general y las dedicadas particularmente al sector industrial empezaron a tener importancia dentro de la economía colombiana en los años cincuenta y sesenta, durante la vigencia del modelo de sustitución de importaciones. Para el caso particular y de acuerdo con Centty (2003), "el modelo exhibió gran dinamismo lo que permitió en un contexto de economía cerrada y mercado interno reducido, realizar un proceso de aprendizaje con importantes logros aunque con algunas limitaciones en materia de equipamiento, organización, escala, capacitación, información, etc." (s. p.). No obstante, este proceso fue afectando negativamente a las pequeñas empresas por la falta de productividad y competitividad, lo que mostró una alta diferenciación con las grandes economías en la apertura económica. En Latinoamérica el sector de las pequeñas y medianas empresas es revalorizado y tomado en cuenta dentro de la perspectiva de las nuevas sociedades. Ahora bien, con la globalización y el crecimiento en general de las transacciones internacionales, las PyME son entendidas como una unidad productiva que está dentro de las escalas más pequeñas:

[estas escalas] se dan a partir de los años 70 debido principalmente a cambios estructurales como el crecimiento de los servicios, es decir que el antiguo paradigma de que solo son empresas aquellas unidades de producción que producen bienes o tangibles cambia rotundamente desde que las facturaciones por servicios de consultorías empresariales, tratamientos clínicos, respaldo o soporte técnico y la valorización del conocimiento como factor de producción de riqueza. (p. 4)

Es aquí donde aparece realmente el valor del servicio y el verdadero valor de la competitividad; así, a diferencia de las empresas convencionales, las PyME generan un valor agregado que aumenta los activos de la empresa, valora al capital humano y da valor a la innovación.

\section{Antecedentes del sector turístico colombiano}

La actividad turística colombiana históricamente no ha sido organizada. En un principio no existía un plan de servicios, como transporte, alimentación y entretenimiento, ligado a la industria turística. En el país lo que primero se desarrolló fue la actividad hotelera.

En nuestro territorio, el desarrollo del turismo ha tenido las mismas facetas de otras naciones ya que en su comienzo fue primitiva y rudimentaria por las precarias condiciones de construcción y comodidad de las posadas que se ubican a la vera de los caminos para el servicio de los viajeros, comerciantes y arrieros. (Moreno, 1981, p. 2)

Desde la época precolombina y hasta comienzos del siglo XIX, "el río Magdalena era la única vía de enlace entre la costa atlántica y el interior del país" (p. 2); por allí cruzaban decenas de comerciantes llevando sus productos al centro del país y buscando sitios donde hospedarse.

En ese contexto y según Moreno (1981), el aumento en la circulación de personas por las cercanías de río Magdalena exigió la construcción de hospedajes para los visitantes en los puertos fluviales: "Fue así como en Honda en 1889, se inaugura el Hotel América el que actualmente funciona y que es considerado como el primero en la Hotelería colombiana. Doce años después y debido al escaso progreso del país se construye en Cali el Menéndez y en 1918 el Lusitania en Ibagué" (p. 2). En los años treinta ya existía un mayor número de hoteles, pero aún no se consolidaba como sector en el país. Su desarrollo data de hace menos de cien años, a pesar de que antes de esa época muchas personas pudieron tener como destino turístico nuestro país. Con la creación en 1931 del Servicio Oficial del Turismo, el Gobierno colombiano le apostó a esta industria como posible generador de crecimiento económico del país (Such, Zapata, Risso, Brida y Pereyra, 2009).

A pesar de la creación del Servicio Oficial de Turismo, es partir de la Segunda Guerra Mundial cuando las relaciones y condiciones laborales cambian (hay menos horas de ocupación de los empleados) y permitieron que las personas tuvieran más tiempo para el ocio. Es por esto que el 
turismo cobra importancia como un renglón económico de desarrollo en las economías del mundo (Sancho, 2004).

A mediados del siglo XX surge la necesidad de fortalecer el turismo por medio de las agremiaciones; así, el diario El Mundo (2012) reconoce en un artículo que las agremiaciones jugaron un papel importante para el sostenimiento y desarrollo del sector turístico colombiano. En 1954, Sr. John Sutherland y otros empresarios hoteleros fundaron por iniciativa propia la Asociación Colombiana de Hoteles (ACOTEL), actualmente llamada COTELCO; otro gremio que apareció a mediados del siglo XX fue la Asociación de Líneas Aéreas Internacionales en Colombia (ALAI$\mathrm{CO}$ ) en la ciudad de Bogotá, cuyo propósito fue agremiar a las aerolíneas que operaban en el país y que tenían vuelos internacionales. Cabe resaltar que hasta ese momento cada gremio velaba por intereses propios y no actuaban de manera mancomunada. Finalmente, la dinámica del sector se tornó interesante para el gobierno nacional, tanto así que surge la idea de crear una entidad que pudiera realizar la planificación de los destinos y el mantenimiento y promoción de atractivos turísticos (espacios que estimulan el turismo). Bajo estas funciones y mediante el Decreto 0272 del 24 de octubre de 1957, la Junta Militar (1957-1958) creó la Empresa Colombiana de Turismo, órgano que direccionaría al sector en el país (Valencia, 1993).

Hacia la década del setenta, según el DNP (2015), existían 316 hoteles registrados en el país, de los cuales cerca del $60 \%$ se concentraban en las ciudades de Bogotá, Medellín y las principales ciudades de la costa atlántica (incluyendo San Andrés). Para esta época, solo existía una cadena hotelera extranjera en el país, Intercontinental Hotels (el carácter de esta cadena consistía en otorgar licencias del uso del nombre en el país). Las construcciones que se realizaban eran hechas por colombianos, de manera que existía una gran participación de capital nacional dentro del sector turístico nacional (Silva, 1977).

En términos generales, el sector turístico no fue tan relevante durante el siglo $\mathrm{XX}$ :

[...] solo tuvo el protagonismo que se pensaba hasta hace unos años atrás, fue en el año 2002 que el turismo realmente comenzó a desarrollarse y establecerse como un motor de crecimiento económico en Colombia, debido al fortalecimiento y presencia de las fuerzas militares gracias a la política de seguridad democrática que estableció el ex presidente Álvaro Uribe Vélez y a la continuidad que le ha dado la administración dirigida por el presidente Juan Manuel Santos. (Hernández, 2014, p. 25)

Esto permitió recuperar la confianza de los ciudadanos y del gobierno y logró reconfigurar la percepción del país en el exterior. Por otra parte, las estrategias implementadas "mediante incentivos tributarios y la recuperación de la inversión extranjera han sido aspectos claves en la trasformación del turismo en Colombia" (Bravo y Rincón, 2013, p. 35).

\section{La Alianza del Pacifico como estrategia de desarrollo económico}

Así como señala Abecé. Alianza del Pacífico, "E1 28 de abril del 2011, los jefes de Estado de Chile, Colombia, México y Perú acordaron en la Declaración de Lima establecer la Alianza del Pacifico con el objetivo de 'avanzar progresivamente hacia la libre circulación de bienes, servicios, capitales y personas" (Alianza del Pacífico, 2013, [s. p.]). Dentro de las negociaciones se invitó a Panamá como Estado observador del proceso y fue así como el 8 de febrero de 2012 los directores de Proexport, ProChile, ProMéxico y PromPerú suscribieron la declaración de cooperación de las agencias de promoción para "promover el comercio exterior y la inversión entre los países miembros, contribuyendo al intercambio de inteligencia comercial, mejores prácticas de promoción de exportaciones y un adecuado fomento a las inversiones" (clubensayos.com/Negocios, 2014).

La última reunión se realizó el 10 de febrero del 2014 en la ciudad de Cartagena, Colombia, en donde se establecieron más protecciones jurídicas a los países integrantes y la desgravación del universo arancelario (el $92 \%$ de los aranceles serían eliminados de forma inmediata, y el restante, 
de forma gradual). Por su parte, el grupo técnico de las PyME definió “intercambiar y difundir prácticas empresariales, formular estrategias para su fortalecimiento e intercambiar información sobre políticas públicas exitosas". Los resultados preliminares de la AP en el marco comercial y del turismo han sido satisfactorios para los países miembros; al respecto, el diario El País (10 de enero de 2016) afirma:

Los efectos positivos del acuerdo comercial entre los cuatro países que conforman la llamada Alianza del

Pacífico (Colombia, México, Chile y Perú) también se perciben en el turismo regional.

El año pasado, por ejemplo, se reportó un incremento del turismo hacia Colombia del orden del $18 \%$ frente al 2013, de acuerdo con la Asociación Colombiana de Agencias de Viajes y Turismo, Anato.

Por su parte, el bloque comercial registró un aumento de $22 \%$ en cuanto a la visita de colombianos a México, Chile y Perú en el 2014. ("Aumenta el turismo", 14 de abril de 2015)

De esta forma, el sector turístico colombiano se ha venido convirtiendo en uno de los pilares de la economía nacional. Aun cuando ha sido un escalafón en cierta forma rezagado, en este sector se encuentra un gran potencial, que además es impulsado por las condiciones geográficas y climáticas que convierte a las distintas regiones colombianas en sitios propicios para ser visitados por nacionales y extranjeros. Con base en esto, se establece un diagnóstico general de la competitividad de las PyME colombianas que se dedican a la prestación de servicios en dicho sector.

En ese orden de ideas, se realiza una prospectiva de las PyME del sector turismo en Colombia para vislumbrar su horizonte en el marco de la AP. Para su realización se desarrolla una aproximación teórica y conceptual que sirve para dar una idea al lector sobre las temáticas a abordar: las generalidades de las PyME, la dinámica del sector turístico en Colombia, los estudios relacionados con la productividad y la competitividad de las PyME; posteriormente, se describe la evolución del sector turístico y el proceso de conformación de centros hoteleros con el propósito de identificar los aspectos generales sobre la AP; luego, se realiza la caracterización de las PyME colombianas del sector turístico, en donde se analizan cuáles son las actividades que se relacionan en el marco de la AP, las variables a analizar (la producción bruta, el valor agregado, los ingresos y el consumo), y por último, se realiza una comparación de las cifras del sector turismo entre los países de la AP, Colombia, México, Chile y Perú, donde se describirán los principales registros de los resultados del sector turismo con el propósito de identificar fortalezas y falencias.

\section{Un contexto de las PyME}

Según Hallberg (2000), "la definición de pequeñas y medianas empresas (PyME) varía de acuerdo a cada país y generalmente está basada en el número de empleados y activos financieros". En este sentido, el comportamiento de las PyME ha evolucionado y encuentra cada vez más posibilidades de crecimiento y oportunidades. Existen modelos que explican este proceso por medio del análisis del comportamiento de internacionalización de las PyME y el nivel de competitividad desde una perspectiva empresarial.

Desde este contexto, Johanson y Vahlne (Johanson y Wiedersheim-Paul, 1975), creadores del modelo de Uppsala en 1970, plantearon el encuentro de oportunidades cuando las empresas enfrentan mercados desconocidos, información incompleta y un estado de permanente incertidumbre. Este modelo se realiza por medio de exploración y un método llamado ensayo y error, que busca la mejor alternativa a partir de diferentes hipótesis tomadas para casos específicos y teniendo en cuenta que se describen principalmente dos pautas en el proceso de internacionalización: i) el desarrollo de la empresa en un país y ii) el desarrollo de la empresa a través de varios países. Así, este modelo predice que la organización "incrementará de forma gradual sus recursos comprometidos en un país concreto a medida que vaya adquiriendo experiencia de las actividades que se realizan en dicho mercado" (Trujillo, Rodríguez, Guzmán y Becerra, 2006, p. 13). 
Según los autores, para lograr este proceso se deben tener en cuenta cuatro etapas: i) actividades esporádicas o no regulares de exportación, ii) exportaciones a través de representantes independientes, iii) establecimiento de una sucursal comercial en el país extranjero y iv) establecimiento de unidades productivas en el país extranjero. Cada vez que se haya logrado completar una de las etapas, la siguiente tendrá un mayor grado de penetración. Todo esto teniendo en cuenta que es un proceso paulatino donde la mayoría de las empresas pequeñas sufren restricciones, como, por ejemplo, la falta de experiencia o de habilidades gerenciales, dificultades en la transición de una firma familiar a una controlada por una gerencia, etc. (Anderson y Gatignon, 1986).

Por ello es importante tener en cuenta la principal hipótesis del modelo: "muchas empresas comienzan sus operaciones internacionales cuando son aun pequeñas y las expanden gradualmente [...] la empresa se desarrolla primero en su mercado nacional y la internacionalización es la consecuencia de una serie de decisiones incrementales" (Aranda y Montoya, 2006, p. 176). Ahora bien, el modelo también especifica que estas ventas en el extranjero comienzan "con órdenes de exportación ocasionales, las cuales serán remplazadas por exportaciones regulares, con lo cual poco a poco las empresas podrán producir cantidades que satisfagan la demanda de sus clientes en el extranjero" (Modelo Upsala, s. f.). En cuanto al resultado del modelo, el proceso se determina:

[...] por un progresivo aumento del conocimiento del mercado debido a la experiencia, y a un mayor compromiso de recursos debido a la necesidad de controlar el proceso internacionalizador. Dicho proceso tendrá lugar primero en los países que se consideran más cercanos psicológica y geográficamente, que son los que ofrecen un mayor grado de similitud al nacional, para posteriormente extenderse a los más distantes, manifestándose así el primer patrón de internacionalización posible. (Aranda y Montoya, 2006, p. 176)

Para poner en práctica el conocimiento adquirido con el modelo de Uppsala se debe tener en cuenta el modelo de planeación sistemática, creado por el mismo autor años después para ser complemento de su anterior modelo; con este modelo se comprende qué tan complejo es el mundo o el mercado en que tienen que desenvolverse. El modelo de planeación sistemática funciona como un típico proceso de planeación (ver figura 1), que corresponde a un esquema general del modelo de planeación sistemática y encuentra la posición interna, el ambiente externo y la ejecución de la estrategia en el ambiente externo, con lo cual se logra la retroalimentación del proceso.

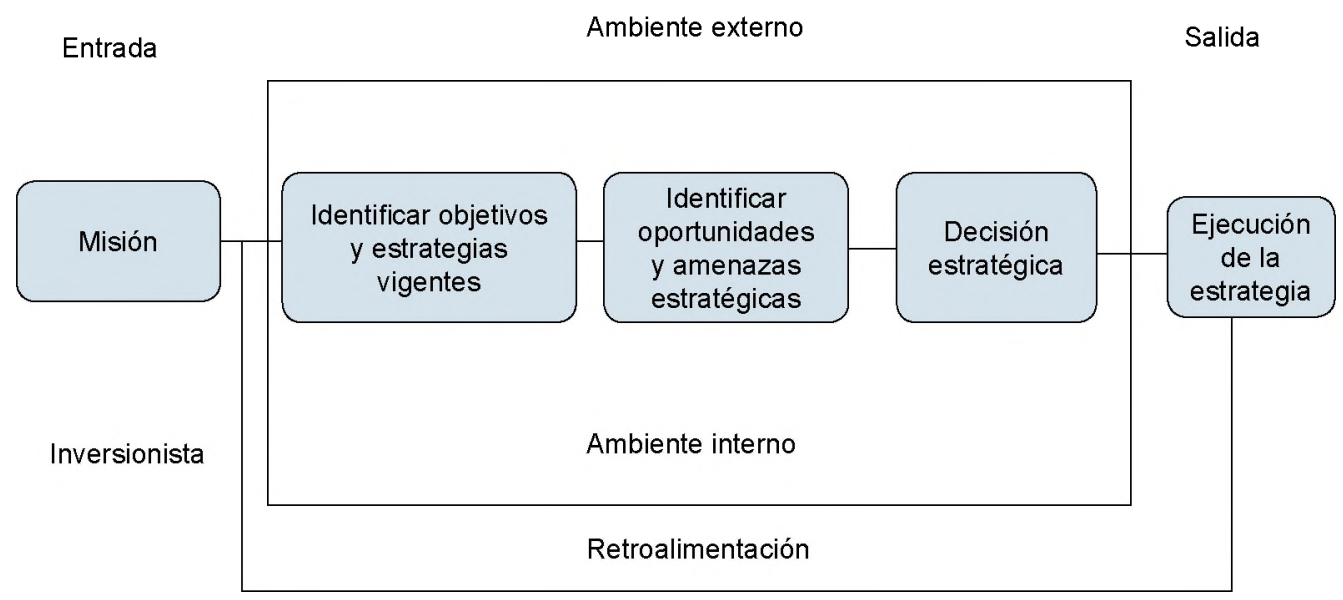

Pasos del proceso de Planeación Estratégica.

Figura 1. Esquema del modelo de planeación sistemática.

Fuente: Li, Li y Dalgic (2004). 
Respecto de los factores de competitividad y su nivel en las PyME, en el esquema clásico del diamante Porter (1990), las fuerzas que mueven la competitividad en un mercado determinado pueden agruparse en cinco grupos: i) poder de negociación de los clientes, ii) poder de negociación de los proveedores, iii) amenaza de nuevos entrantes, iv) amenaza de productos sustitutivos y v) rivalidad entre los competidores. Dentro de este esquema existen factores internos y externos que influyen en el desarrollo de la estrategia competitiva de la empresa. Los factores externos son las oportunidades y amenazas de tipo económico y técnico, y los internos, los puntos fuertes y débiles de la empresa, así como los valores personales y profesionales del personal clave. En el caso que nos ocupa, en una PyME, lo fundamental es el empresario. En la figura 2 se da una explicación de los factores influyentes en el desarrollo de estrategias competitivas, encontrando los factores determinantes de la competitividad.

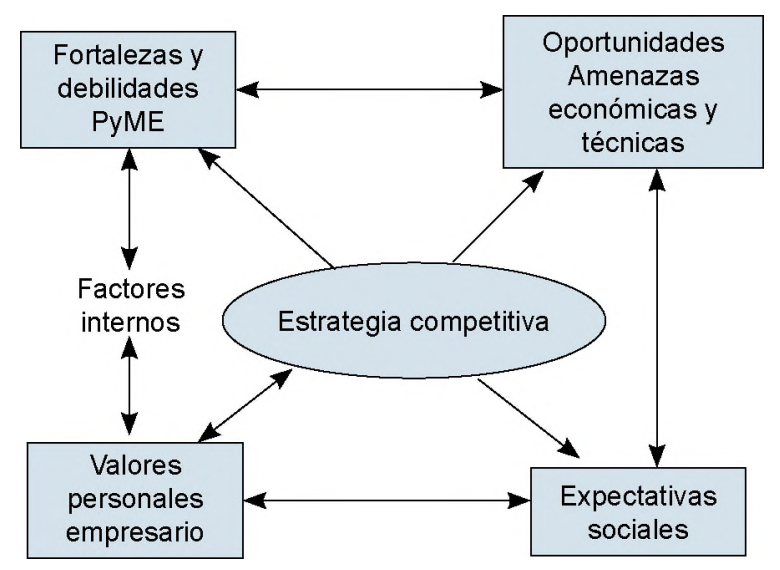

Figura 2. Contexto en que se ve la formula estrategia competitiva de la empresa.

Fuente: Porter (1989).

Lo anterior lleva a considerar que para el caso de las PyME, la aplicación de modelos de productividad y competitividad basados en aspectos propiamente de internacionalización y comercio (más los procesos de integración y perspectiva organizacional en el marco de la administración de este tipo de empresas) pueden reconfigurarse para fortalecer cada uno de los aspectos de la organización frente a la dinámica de la economía de mercado. Zorro (2009), por ejemplo, plantea la liberación de las PyME, así como los incentivos a la mediana y pequeña empresa con educación, excepciones tributarias, la intensificación de la producción y la capacitación para la integración de cadenas productivas. En este sentido, el autor señala que las pequeñas y medianas empresas colombianas frente a la globalización son precisamente las mismas:

[...] el segmento de organizaciones productivas que ofrecen mayor potencial para contribuir positivamente al proceso de reconfiguración del espacio contemporáneo, en el que el papel de lo local se fortalece considerablemente por su carácter de nodo articulador de impulsos de diversas índoles dentro de la red global. (Angarita, 2014, p. 4)

Con base en dicha afirmación, se encontró que las PyME, especialmente las colombianas, tienen poca ocurrencia en el mercado internacional, por sus diferentes problemas, ya sean ligados a la baja competitividad o la escasa asociatividad. Aun así y pese a estas limitaciones:

[...] sus actitudes resultan positivas frente a la realidad de los procesos económicos contemporáneos y la nueva escala de referencia global, lo que genera expectativas favorables en cuanto a la búsqueda de 
sistemas de producción y gestión (hacia dentro y hacia fuera) más eficientes" (Zorro, citado en Serna, 2015, p. 159).

En el artículo de Ochoa (2011), "Las PyME y el comercio exterior: ¿por qué es necesario un plan de exportación?”, se muestra la importancia de las PyME en el comercio internacional y la serie de inconvenientes que estas presentan y que terminan en fracaso al tratar de incursionar en dicho mercado. De acuerdo con lo anterior, se establece la importancia de estudiar cada posibilidad antes de tomar esta importante decisión, más cuando se está en el auge de la globalización, en donde se realizan tratados y alianzas estratégicas de integraciones y de cooperación económica, y cambian las hipótesis, los mercados y los clientes.

En cuanto a la internacionalización de las PyME de alta tecnología en Bogotá, Cardozo, Chavarro y Ramírez (2013) exponen un estudio de caso en el que se da a conocer los diferentes marcos teóricos para comenzar una internacionalización y generar nuevas expectativas incorporando la alta tecnología. La conclusión es que las PyME que se insertan en la globalidad y aquellas que aun teniendo las condiciones para esto prefieren mantenerse aisladas por el miedo a fracasar y perder definitivamente todo tipo de mercado.

En otro estudio, Paternina (2010) muestra la importancia que tiene para las diferentes organizaciones y empresas el manejo adecuado de la gestión del conocimiento; temática que es un punto clave para garantizar la competitividad en una economía dinámica, abierta e impulsada por la globalización. De esta manera, se evidencia la importancia que juega la dimensión tecnológica en la determinación del éxito empresarial; con base a lo anterior, Paternina (2010) propuso un modelo de gestión basado en tres pilares: i) un sistema de información que permita la obtención de datos importantes procedentes de fuentes internas o externas; ii) un sistema de información que permita archivar documentación y que sea accesible a cualquier área funcional, y iii) una cultura organizacional que fomente el intercambio de conocimiento continuo.

Ordosgoitia y Ochoa (2006) realizaron un estudio en donde evidenciaron que $70 \%$ de las empresas pertenecientes al sector turístico de Cartagena no encuentran ningún interés en alcanzar relaciones asociativas de tipo financiero y más del $80 \%$ de las empresas del sector desean alcanzar objetivos estratégicos que incluyan planes promocionales y el intercambio de información. De igual forma, hay que resaltar que los autores encontraron que el aumento del número de asociaciones posibles e identificables del gremio impacta en mayor proporción en la utilidad de los empresarios, puesto que guarda una relación proporcional con esta. Por último, las falencias más graves se encuentran en temas relacionados con la falta de creación de programas de formación, investigación, desarrollo y financiamiento.

Montoya, Montoya y Castellanos (2010) realizaron un estudio en el cual se exploraron los principales factores que influyen en la competitividad de las PyME en Colombia. Para esto, se analizaron las dificultades que estas empresas enfrentan, en especial de aquellas catalogadas de tipo macro y microeconómicos, con el fin de contribuir al mejoramiento de la competitividad. Como resultado, se propuso una mayor integración entre las empresas, lo cual ha demostrado ser una alternativa altamente eficiente para alcanzar rápidamente avances en términos de competitividad.

Lo anterior ha permitido evolucionar en procesos metódicos que han fortalecido los análisis de las PyME desde diferentes enfoques. Saavedra (2012), por ejemplo, realizó un análisis a las PyME latinoamericanas con el enfoque sistemático de competitividad propuesto por la CEPAL, que sostiene que la competitividad de la empresa radica en la interacción de diferentes niveles: a) macro (entorno económico, político, social, etc.), b) meso (entorno regional, infraestructura, educación, nivel de vida) y c) micro (factores internos de la empresa). Para el nivel se utilizó la herramienta mapa de competitividad del BID, en el cual se consideró la diferencia existente entre los sectores como industria, comercio y servicio y tamaños de la empresa (micro, pequeña y mediana). 


\title{
La Alianza del Pacifico y su proceso de integración con las PyME
}

\author{
Según León y Ramírez (2014):
}

La Alianza del Pacífico es un acuerdo de integración y cooperación económico-comercial, creado en abril de 2011; su predecesor fue el Arco del Pacífico Latinoamericano y aglutina las economías de Chile, Colombia, México y Perú. Los gobiernos de las cuatro economías tienen gran afinidad política y económica; además, han suscrito acuerdos de libre comercio entre sí. El 10 de febrero de 2014, el gobierno de Costa Rica firmó el acuerdo que le permitirá convertirse en miembro de la Alianza, aunque este proceso durará un año y estará sujeto al escrutinio de la candidatura. La AP cuenta con 32 observadores; en la primera mitad de 2014, Israel, Bélgica y Trinidad y Tobago fueron los últimos países en adquirir tal estatus. (p. 4)

Según Abecé de la Alianza del Pacifico (AP, 2015), con estos objetivos se clarifican las metas y se unifican las necesidades, las cuales se convierten en beneficios o desventajas en un periodo determinado:

Chile, Colombia, México y Perú tienen una estructura institucional democrática sólida, con mandatarios elegidos periódicamente, mercados dinámicos y globalizados y condiciones favorables para la inversión. De acuerdo a Doing Business 2012 del Banco Mundial (2011), de los 32 países de la región de América Latina y el Caribe, Chile, Perú, Colombia y México ocupan el primer, tercer, cuarto y quinto puesto, respectivamente, en el ranquin de facilidad de hacer negocios. (s. p.)

De esta manera, cuando se formalizan acuerdos internacionales y bloques económicos entre países, se abren automáticamente más posibilidades de expansión en cuanto a mercado, flujo de capitales, personas, entre otros. Este fenómeno es uno de los causantes de que la globalización se esté dando de una manera tan rápida y automática, y genere de forma paralela posibilidades de crecimiento o de rezago. Por lo mismo, con los acuerdos internacionales se desarrollan políticas especiales que vinculan a los socios comerciales, las cuales se crean por medio de grupos técnicos ${ }^{1}$ que definen las prioridades técnicas y obstáculos de cada objetivo.

Según la perspectiva del Ministerio de Comercio, Industria y Turismo de Colombia (MINCIT), formar parte de un sistema productivo más grande permite: consolidar cadenas globales de producción entre los países integrantes, generar más competitividad y aprovechar las oportunidades comerciales que se abren automáticamente en el mercado asiático. Es por eso que desde las PyME se busca integración (entre otras estrategias) a través del intercambio de experiencias e información para fortalecer este tipo de empresas; adicionalmente, se da la oportunidad de "trabajar en el desarrollo de iniciativas sobre emprendimien to e innovación y de establecer canales de diálogo con los empresarios para conocer sus propuestas y preocupaciones frente al desarrollo económico y el ambiente de negocios" (MINCIT, s. d.).

Por lo anterior, el apoyo a las PyME se ha convertido en uno de los ejes estratégicos de la política industrial de Colombia; política que busca profundizar las buenas prácticas empresariales y la modernización de las mismas. Entre los grandes proyectos de apoyo se encuentran:

i) desarrollo de proveedores, ii) aprovechamiento del mercado en la región, iii) posibilidades de exportación conjunta con otros mercados, iv) fortalecimiento a actividades economías de alto potencial, v) mejora regulatoria y armonización de reglas, vi) profundización del libre comercio, vii) creación de un fondo de infraestructura mejorar la competitividad de los países y viii) trabajos conjuntos en materia de política de innovación y emprendimiento. (MINCIT, 2016, p. 84)

Por último se han acordado intercambios de experiencias y buenas prácticas en materia de políticas públicas para las PyME. A 2015 se han realizado cuatro encuentros de intercambio

\footnotetext{
${ }^{1}$ La AP tiene cinco grupos técnicos: a) Comercio e Integración, b) Servicios y Capitales, c) Cooperación, d) Movimiento de Personas de Negocios y de Facilidad para el Transito Migratorio y e) Asuntos Institucionales (AP, 2013).
} 
de experiencias en el marco del proyecto Sinergia entre los Países de la Alianza Pacífico para el Mejoramiento de la Competitividad de las MIPyMES, de donde se han originado iniciativas para la creación de la red nacional de emprendimiento.

\section{Resultados}

\section{Las PyME colombianas del sector turístico y la estrategia de competitividad}

Según el Departamento Administrativo Nacional de Estadística (DANE), el turismo se define como:

[...] un fenómeno social, cultural y económico que lleva consigo el movimiento de personas. La relación del turismo con una gran variedad de actividades económicas ha fomentado el interés en medir su contribución económica, principalmente en los lugares visitados y en evaluar su interdependencia con otras actividades sociales y económicas. (2015, p. 3)

Como ya se señaló, con la conformación de la Oficina de Turismo en 1931, Colombia dio un primer paso para organizar la actividad turística como un sector; sin embargo, el protagonismo que se pensaba apenas llegó en 2002, fecha en la que realmente el turismo comenzó a desarrollarse y establecerse como un motor de crecimiento económico en Colombia. Este crecimiento se debió a las políticas estatales que a partir de esa fecha se encargaron de generar una imagen de confianza y seguridad en todo el territorio colombiano, lo que, a su vez, estaba asociado al fortalecimiento y presencia de las fuerzas militares y la recuperación de la soberanía del estado colombiano. Con estos cambios se ha logrado cambiar la percepción del país en el exterior.

La geografía colombiana, caracterizada por la biodiversidad, los atractivos naturales y culturales, los dos océanos (el Pacífico y el Atlántico), las 58 áreas naturales protegidas (que forman parte de una red de parques nacionales), entre otros factores, ha favorecido la mejora de oferta del turismo en diferentes aspectos o actividades (Bravo y Rincón, 2013). Adicional a esto, se ofrece turismo de playas, lugares históricos, cultura, agroturismo, ecoturismo, deporte, salud, ferias, negocios. Toda esa serie de ventajas naturales del país hacen que se pueda posicionar el sector como una fuerte industria dentro de los servicios que Colombia puede ofrecer tanto para turistas nacionales como extranjeros. Actualmente, el sector no solo involucra los hoteles o lugares de alojamiento en el país, sino también otro tipo de actividades. Ha sido tan importante este proceso, que el desarrollo que ha tenido este sector logra según la clasificación industrial internacional uniforme, agruparlas en cinco categorías relacionadas con el turismo, las cuales incluyen actividades como: alojamiento, restaurantes, transporte, agencias de viajes y esparcimiento.

La importancia del sector se ve reflejada en el número de actividades que involucra el turismo en el país. Son más de veinte actividades que guardan una estrecha relación con el sector turístico, en el que se incluyen desde las relacionadas al esparcimiento, hasta el transporte y las agencias de viajes. Teniendo en cuenta la Encuesta Anual de Servicios (EAS) de 2012, las cinco categorías produjeron en conjunto más de $\$ 14$ billones y generaron un valor agregado de $\$ 6.1$ billones; cifra para nada despreciable, teniendo en cuenta que es un sector relativamente nuevo para la economía colombiana. En el figura 3 se puede observar un resumen de las principales variables del sector, en el cual se evidencia una marcada tendencia creciente en los últimos años. Los valores de la producción bruta, ingresos, consumo intermedio y valor agregado se han duplicado en un periodo de seis años para dicho sector, lo que habla de la buena dinámica del turismo en estos años. 


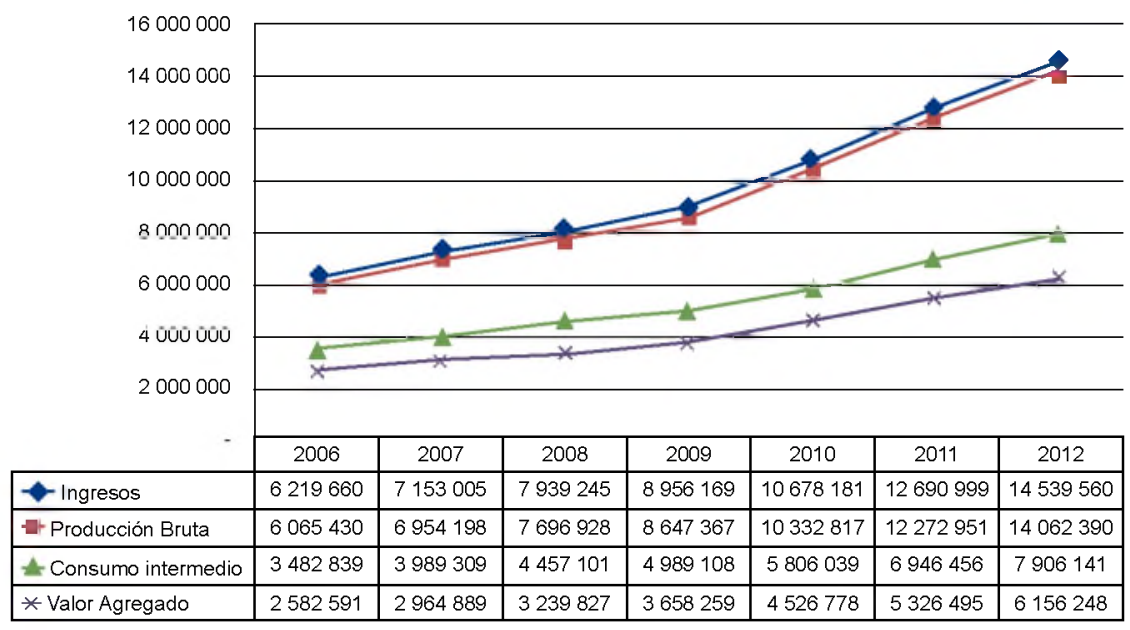

Figura 3. Principales variables del sector turístico colombiano periodo 2006-2012 (valores en millones de pesos).

Fuente: DANE (2012)

Esta tendencia se extiende no solo a valores corrientes, sino a variables reales como el personal ocupado en el sector (figura 4) que presentan una tendencia similar. A medida que aumenta la producción bruta, es necesario que el sector completo demande personal de manera significativa para sustentar los crecimientos en la producción.

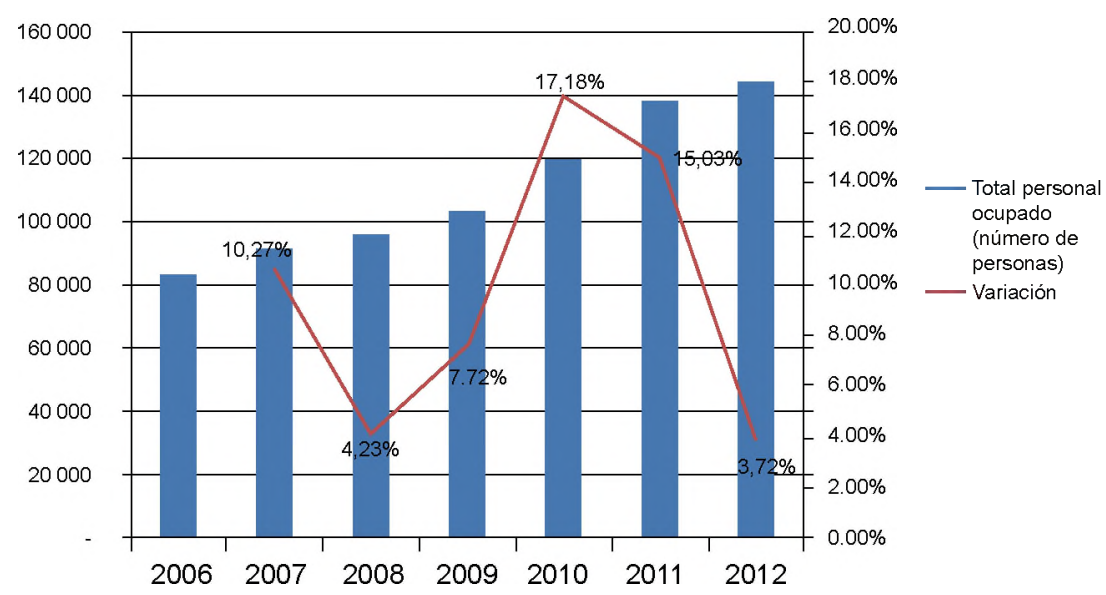

Figura 4. Personal ocupado por el sector turístico colombiano y su crecimiento periodo 2006-2013.

Fuente: DANE (2012).

E1 sector turístico en el periodo 2006-2012 tuvo un promedio de crecimiento de $9.69 \%$ anual; 2010 y 2011 fueron los años más favorables, con una tasa de $17.18 \%$ y $15.03 \%$, respectivamente. Para el año 2012 el turismo ocupó el 9.7 \% (144 174) del personal total ocupado por los servicios, así que dentro del sector es un campo que genera gran número de empleos. Si bien para el último año del periodo el crecimiento solo alcanzo $3.7 \%$, cabe resaltar que nunca ha tenido periodos negativos de crecimiento. 
Como se indicó anteriormente, el sector turismo agrupa cinco categorías (o subsectores), cada una de las cuales corresponden a actividades diferentes que se relacionan en torno al turismo. Dentro de la producción bruta (ver figura 5), la categoría de transporte es la que tiene mayor participación en todos los años analizados, con lo cual se concluye que es la actividad primordial dentro del sector turismo. Caso contrario ocurre con la categoría hotelera o de alojamiento, la cual ocupa el tercer lugar; así, para 2012, tan solo alcanzó la mitad de la producción obtenida en la categoría de restaurantes. Lo que resalta que la categoría de transporte y de restaurante representa para este mismo año un total de $64 \%$ de la producción bruta del sector.

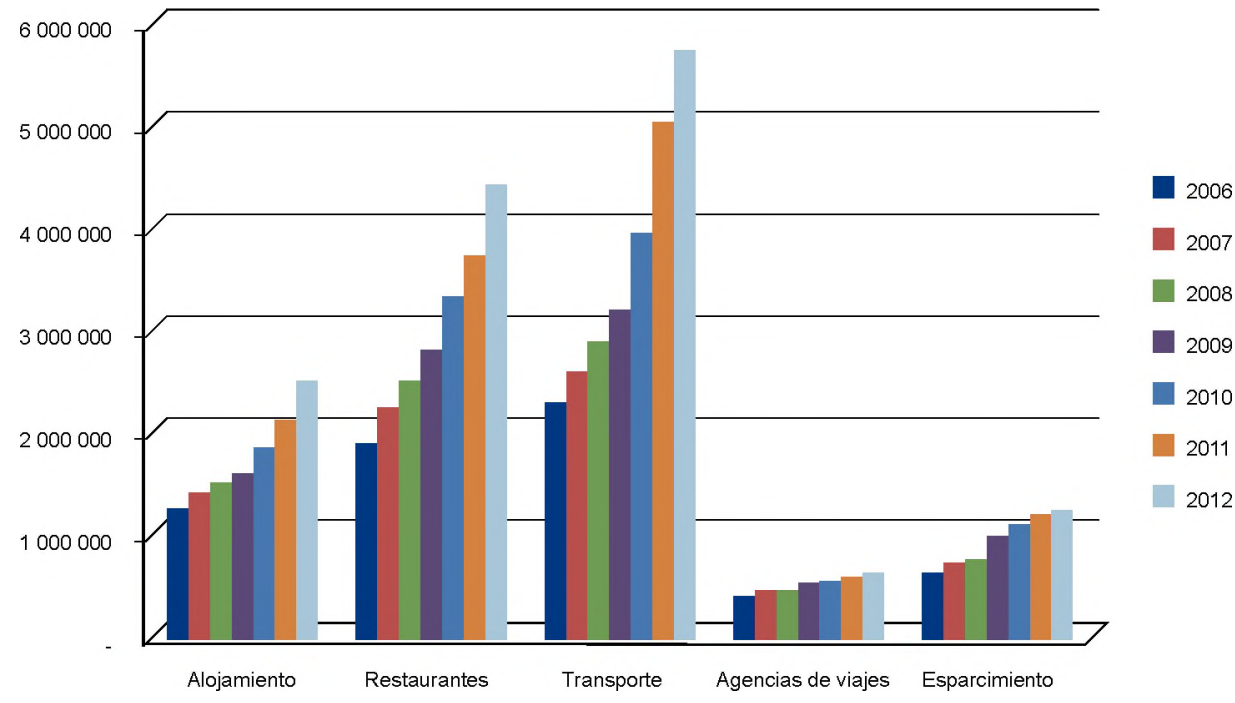

Figura 5. Composición de la producción bruta por categorias del sector turismo, periodo 2006-2012 (en millones de pesos).

Fuente: DANE (2012).

Las categorías más rezagadas dentro del sector son las agencias de viajes y las actividades relacionadas con el esparcimiento; ambas categorías tienen un espacio relativamente nuevo dentro del sector, por lo cual aún es prematuro esperar una gran participación. Sin embargo, el esparcimiento ha logrado duplicar su aporte de producción bruta y llegó a superar el billón de pesos en el año 2012.

El panorama no cambia en la participación dentro del valor agregado. Para 2012, casi la mitad del valor agregado producido por el sector, es decir, el $44 \%$, recae sobre el subsector transporte; cifra que solo puede ser igualada por las categorías de alojamiento y restaurantes en conjunto (cerca de $40 \%$ ), lo cual evidencia la dependencia del sector hacia la categoría transporte. La razón principal por la que el transporte representa una mayor participación es porque es una actividad que no solo contabiliza la movilidad de turistas hacia nuestro país, sino que, a su vez, implica toda la movilidad interna entre turistas nacionales e internacionales, lo cual genera mayores flujos de uso que las demás categorías. 


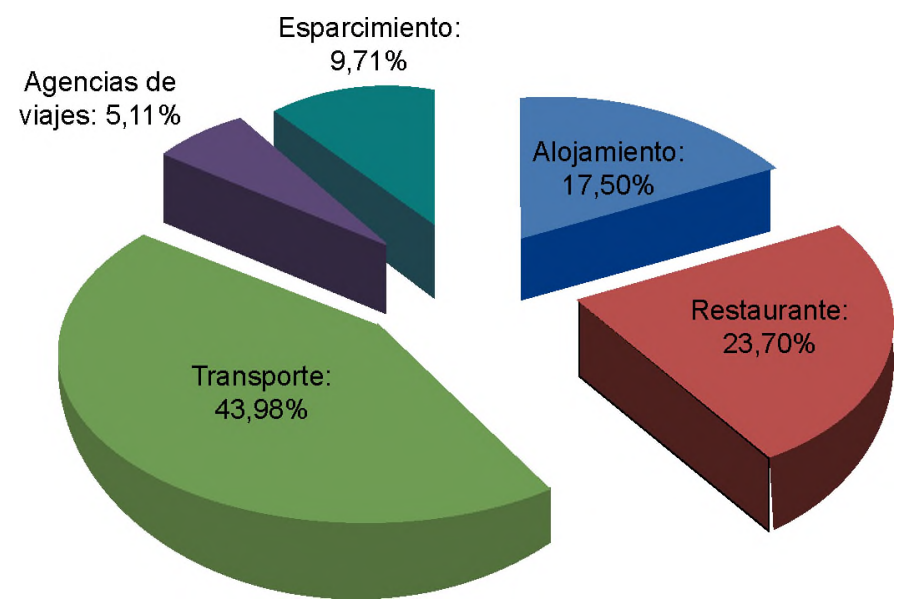

Figura 6. Part. (\%) categorías turísticas dentro del valor agregado para el sector (2012).

Fuente: DANE (2012).

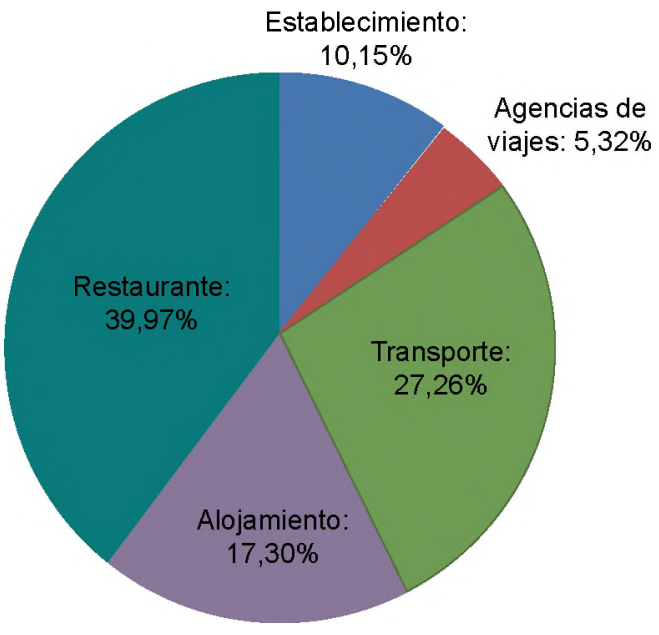

Figura 7. Participación del sector turismo en el personal ocupado por categorías.

Fuente: DANE (2012).

La actividad de restaurantes tiene un impacto importante en la absorción de personal ocupado; para 2012, según el DANE (2012), esta categoría sumó 39.9\% del total de personal ocupado de la industria, seguido por las categorías transporte (27.2\%) y alojamiento (17.3\%). La tendencia de estas tres categorías se asocia a la naturaleza de la actividad: son las que más personal absorben y las que requieren menos calificación para brindar servicios, ya que, por ejemplo, en las de agencias de viajes y esparcimiento se necesitan personas con una preparación educativa superior, si se las compara con las labores que se realizan en hoteles y transporte terrestre.

En la Encuesta anual de servicios 2012 (DANE, 2012) hay una relación de variables que pueden ayudar a observar la productividad del sector. El DANE mide la productividad en la relación entre los ingresos sobre la suma del consumo intermedio y los gastos del sector, de esta manera se observa qué tan importante es el nivel de ingresos generados en el sector por cada una de sus categorías. 


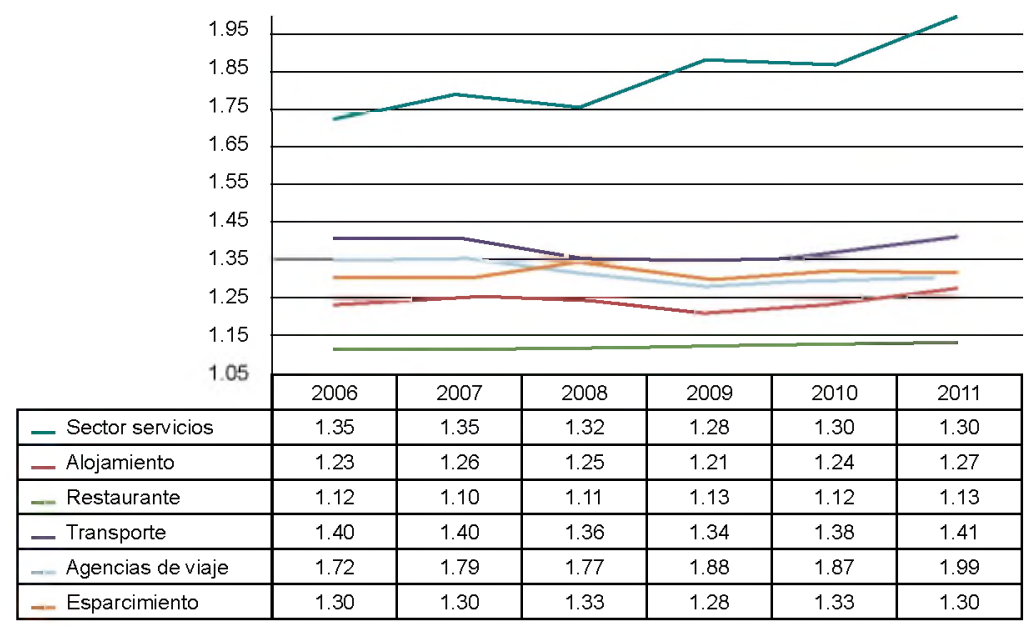

Figura 8. Dinámica de la productividad de las categorías sector turismo vs. sector servicios colombiano 2006-2011 (\%).

Fuente: DANE (2012).

La dinámica de este indicador de productividad de las categorías con respecto a todo el sector de servicios presenta un buen comportamiento en el periodo 2006-2011. Existen dos categorías que siempre se encuentran por encima de la productividad total del sector servicios: transporte y agencias de viaje. El caso de las agencias de viajes es bastante particular, ya que para 2011 tuvo casi $200 \%$ de productividad, muy por encima de la medida para los servicios (130\%); esta tendencia se presenta porque esta categoría es la que menos personal ocupa y, por ende, el gasto asociado a este parámetro es bajo, aun cuando su consumo intermedio es alto.

La categoría transporte tiene un indicador mucho menor de productividad (140\%), y también logra superar la productividad del sector servicios; sin embargo, la tendencia creciente de esta categoría es mucho menor que la de agencias de viajes, en parte porque la dinámica del personal ocupado se ha duplicado desde 2006 hasta 2011, lo que implica muchos más gastos de personal. La categoría de restaurantes es aparentemente la menos productiva dentro del sector; no obstante, se debe tener en cuenta que su relación de consumo intermedio y de gasto en personal es de la más grande dentro de las categorías. Los índices de ingresos de esta última categoría no alcanzan una cantidad mayor respecto a sus egresos, lo cual lo imposibilita para tener una dinámica de productividad mejor. Aun así, es rescatable el hecho que esta presenta una tendencia constante sin fluctuaciones negativas en la productividad.

Finalmente, existe una relación importante del valor agregado sobre personal remunerado, con lo cual se analiza si en realidad el personal ocupado genera una cantidad significativa de valor agregado y qué tan productivos son. En este caso, el transporte recupera su posición de líder dentro de las categorías; esto es apenas lógico, ya que como se resaltaba en la caracterización general, el transporte produce más del $40 \%$ de todo el valor agregado del turismo; por esta razón, su relación de valor agregado y personal es para 2012 de casi 70 unidades por persona ocupada, lejos de las 41 unidades que logró la categoría de agencias de viaje para este mismo periodo.

Las categorías diferentes de transporte tienen un comportamiento dinámico similar, cuyos valores oscilan entre el 40.83 y el 43.20 . En este caso queda exento el sector restaurante, el cual presenta un aporte de $20 \%$, aproximadamente, y que ocupa el último lugar, lo que evidencia que es una de las categorías que más involucra personal, lo cual hace que la distribución del valor agregado per cápita sea la más baja para todos los periodos. 


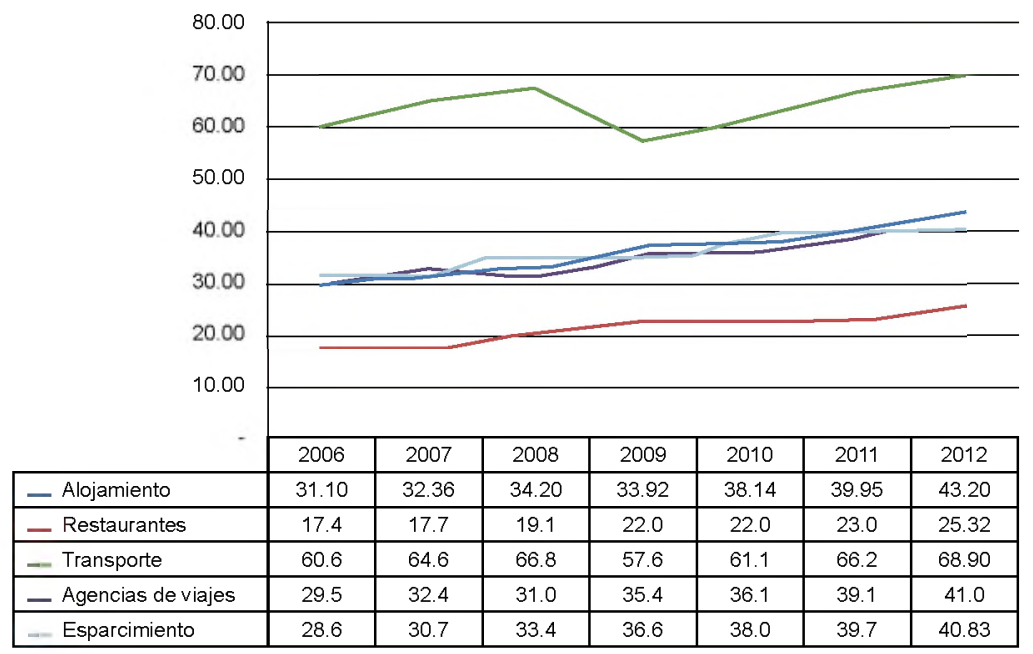

Figura 9. Evolución de la relación entre valor agregado/personal ocupado en las categorías del sector turístico colombiano 2006-2012.

Fuente: elaboración propia basado en la DANE (2012).

\section{Situación actual del turismo colombiano}

Colombia ha reportado un aumento interesante en el sector turismo (ver figura 10), que se evidencia en un crecimiento mayor que los indicadores mundiales; así, según datos de Migración Colombia-Proexport, el crecimiento mundial entre 2001 y 2011 fue de $3.4 \%$ y el de Colombia fue de $10.3 \%$, lo que evidencia que ha mejorado anualmente (Bravo y Rincón, 2013).

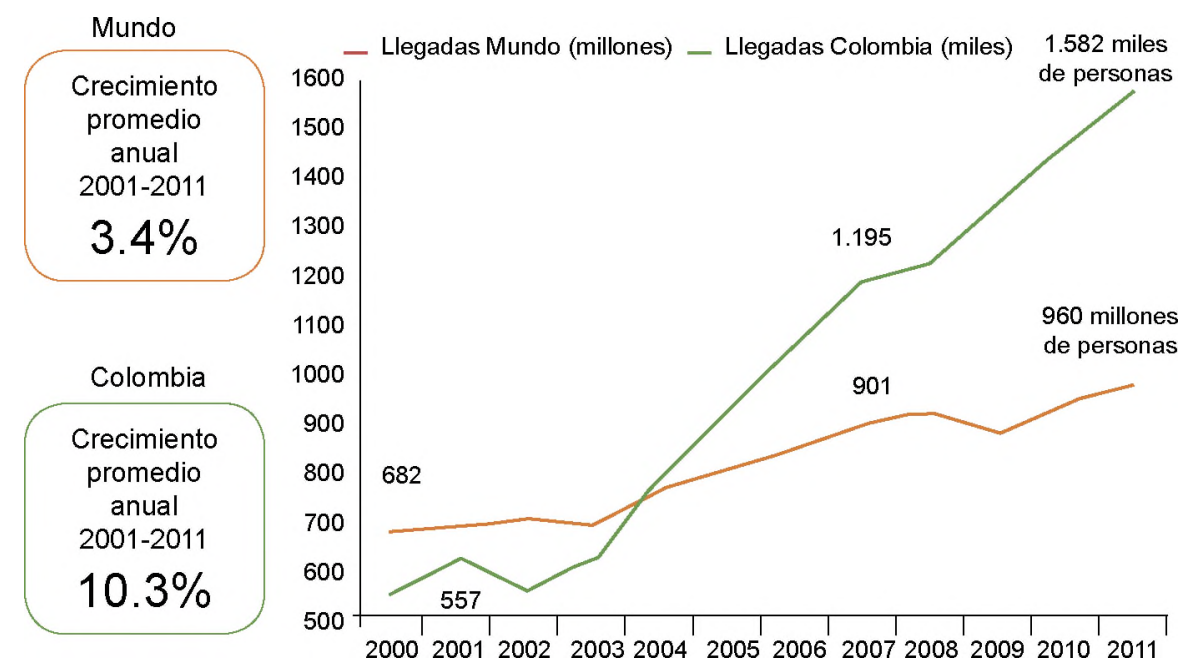

Figura 10. Comparativo dinámica de crecimiento llegadas internacionales a Colombia y al mundo 2000-2011.

Fuente: Migración Colombia. Cálculos Proexport (2012, p. 3).

Para analizar el crecimiento del sector en los últimos años es importante mostrar cómo ha sido la evolución de Colombia en el ámbito mundial y su participación en la región latinoamericana 
(Bravo y Rincón, 2013). La llegada de viajeros al país creció de manera constante en los últimos ocho años; en el 2012 llegaron a Colombia más de 1.6 millones de extranjeros, lo que representó un crecimiento de $7 \%$ comparado con el año inmediatamente anterior. La dinámica de extranjeros que arriban a Colombia se ha duplicado en los últimos ocho años, lo que evidencia la importancia de Colombia como destino turístico.

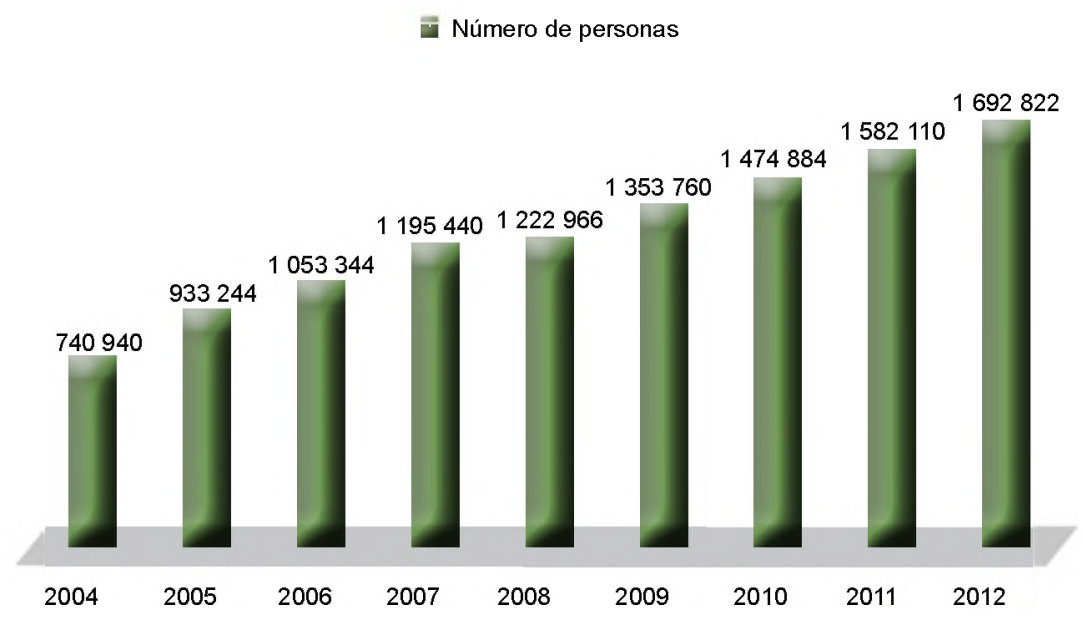

Figura 11. Llegadas de viajeros extranjeros a Colombia por año (2004-2012).

Fuente: Migración Colombia, cálculos de Proexport (2012).

En cuanto a la procedencia de los turistas que vinieron a Colombia en el periodo 2005-2012, los tres países con mayor flujo de viajeros fueron Estados Unidos, Venezuela y Ecuador (en ese orden importancia). A pesar de la crisis política que se tuvo con Venezuela entre 2003 y 2010, este país nunca cedió el segundo lugar en el número de turistas que arribaron a Colombia. Aquí es importante resaltar que a partir del 2007 los países miembros de la AP se posicionaron entre las diez nacionalidades con mayor flujo de turistas. México y Perú han sido países que todos los años reportaron viajeros hacia Colombia; por su parte, desde 2007, Chile ingresó al puesto diez y en el año siguiente tuvo el noveno lugar, que lo ha mantenido hasta 2012.

Centrándose en los destinos por país y en el marco de la AP, es significativa la participación de Perú, México y Chile en el flujo de ingreso de turistas extranjeros a Colombia entre 2010 y 2012. Estos tres países miembro de la AP se encuentran entre los principales aportantes de turistas para Colombia; por su parte, Perú fue el que más viajeros aportó, con 88844 personas para 2012.

En la tabla 1 se puede observar que Perú, México y Chile presentan una dinámica positiva en torno al flujo de viajeros que llegan a Colombia. Las tasas de crecimiento del $16.6 \%$ de Perú y $35.8 \%$ de Chile muestran que Colombia se ha convertido en un destino importante para los viajeros de dichos países. La tasa de México, a pesar de ser la más baja para 2012 (8.1\%), evidencia que en periodos anteriores aportó un buen número de viajeros: presentó tasas de $18 \%$ y $16.2 \%$ para 2010 y 2011 , respectivamente. En 2012, los tres países en conjunto aportaron 250230 viajeros del total de las llegadas al país, lo que equivale a $14.7 \%$ del total de los viajeros en ese año; una cifra nada despreciable, atendiendo a la dinámica de sus tasas de variación, las cuales son favorables para estos tres países. En este sentido, puede esperarse que con las facilidades para la movilidad de personas acordadas en la AP, la participación de estos países se incremente y sea beneficioso para la industria turística colombiana. 
En términos macroeconómicos y de acuerdo Bravo y Rincón (2013):

[...] el turismo se posiciona como el tercer sector generador de divisas para Colombia, después del petróleo y el carbón, y por encima de productos tradicionales como el café, las flores y el banano según Proexport, lo cual permite ver el crecimiento y aporte que está logrando este sector al país, con unos ingresos de COP\$ 3.114 millones de divisas por este concepto en el año 2011 y COP\$ 3.137 millones hasta finales del segundo semestre del 2012, logrando una cifras importantes que resaltan el buen comportamiento y dinámica que ha tenido el sector. (p. 44)

Tabla 1. Variación de llegadas por nacionalidad 2010-2012

\begin{tabular}{|c|c|c|c|c|c|c|c|}
\hline & & 2010 & 2011 & 2012 & $\begin{array}{c}\% \text { Var. } \\
2010 / 2009\end{array}$ & $\begin{array}{c}\% \text { Var } \\
2011 / 2010\end{array}$ & $\begin{array}{c}\% \text { Var } \\
2012 / 2011\end{array}$ \\
\hline 1 & $\begin{array}{l}\text { Estados } \\
\text { Unidos }\end{array}$ & 345536 & 317962 & 319202 & $10.8 \%$ & $-8.0 \%$ & $0.4 \%$ \\
\hline 2 & Venezuela & 197173 & 228934 & 250404 & $-17.2 \%$ & $16.1 \%$ & $9.4 \%$ \\
\hline 3 & Ecuador & 122076 & 108917 & 114564 & $19.9 \%$ & $-10.8 \%$ & $95.2 \%$ \\
\hline 4 & Argentina & 83674 & 93822 & 111555 & $36.4 \%$ & $12.1 \%$ & $18.9 \%$ \\
\hline 5 & España & 80829 & 88383 & 94805 & $3.7 \%$ & $9.3 \%$ & $7.3 \%$ \\
\hline 6 & Perú & 79275 & 77529 & 88844 & $2.0 \%$ & $-2.2 \%$ & $14.6 \%$ \\
\hline 7 & Brasil & 66309 & 93227 & 85947 & $39.6 \%$ & $40.6 \%$ & $-7.8 \%$ \\
\hline 8 & México & 67818 & 78827 & 85232 & $18.0 \%$ & $16.2 \%$ & $8.1 \%$ \\
\hline 9 & Chile & 45379 & 56090 & 76154 & $25.5 \%$ & $23.6 \%$ & $35.8 \%$ \\
\hline 10 & Canadá & 32886 & 38394 & 44497 & $16.8 \%$ & $16.7 \%$ & $15.9 \%$ \\
\hline 11 & Alemania & 29547 & 41166 & 42423 & $13.0 \%$ & $39.3 \%$ & $3.1 \%$ \\
\hline 12 & Francia & 33878 & 37829 & 38920 & $11.6 \%$ & $11.7 \%$ & $2.9 \%$ \\
\hline 13 & Italia & 28847 & 29597 & 29945 & $10.7 \%$ & $2.6 \%$ & $1.2 \%$ \\
\hline 14 & Panamá & 33760 & 32454 & 30654 & $9.1 \%$ & $-3.9 \%$ & $-5.5 \%$ \\
\hline \multirow[t]{3}{*}{15} & Reino Unido & 20760 & 25473 & 23801 & $9.8 \%$ & $22.7 \%$ & $-6.6 \%$ \\
\hline & Resto & 207137 & 233506 & 255875 & $13.1 \%$ & $12.7 \%$ & $9.6 \%$ \\
\hline & Total & 1474884 & 1582110 & 1692822 & $8.9 \%$ & $7.3 \%$ & $7.0 \%$ \\
\hline
\end{tabular}

Fuente: Migración Colombia-Cálculos Proexport (2012).

\section{Calidad del sector turismo en el marco de la politica de competitividad}

El concepto de calidad turística también es tenido en cuenta dentro de las políticas del gobierno colombiano para el sector, ya que asegurar la calidad genera competitividad mundial como destino turístico. En 2012, el viceministerio de turismo planteó normas técnicas sectoriales (NTS), las cuales buscaron establecer reglas para el buen funcionamiento de las actividades turísticas de cada región en Colombia (Bravo y Rincón, 2013). A continuación y a modo de resumen, se mencionan las normas técnicas sectoriales aplicables al sector turismo en Colombia con las cuales se pretende alcanzar la calidad del sector: a) establecimientos gastronómicos, b) tiempo compartido, c) turismo sostenible, d) guías de turismo y e) agencias de viajes. ${ }^{2}$ En resumen, cada una de estas normas tiene como objetivo cubrir los diferentes frentes de la actividad turística en el país, con la intención de homogenizar los criterios, normas y requisitos de acuerdo a los estándares internacionales, lo que finalmente orientará las actividades del turismo colombiano hacia estándares altos de calidad en el ámbito mundial.

\footnotetext{
${ }^{2}$ Datos recuperados de https://www.mincomercio.gov.co/publicaciones.php?id=16197
} 


\section{La competencia de las PyME colombianas del sector turístico en el contexto de la Alianza del Pacífico}

Según cifras del DANE (2015), en el periodo 2006-2012 el sector turístico colombiano tuvo un comportamiento creciente en cuanto al personal ocupado. Específicamente, entre 2008 y 2010 se presentó la mayor tasa de incremento, que llegó a alcanzar porcentajes de hasta $17.18 \%$ con respecto al año anterior. En total, en 2012 se alcanzó un valor superior a los 140000 trabajadores, aun cuando este comportamiento ha representado una tasa decreciente desde el año 2010. Dentro de las diferentes actividades, es la de restaurantes la que requieren de mayor número de trabajadores, con un porcentaje de $39.97 \%$, seguido de transporte, con $27.96 \%$ y alojamiento, con $17.30 \%$.

E1 mayor porcentaje de la producción turística lo representa directamente el transporte, con un valor de $43.98 \%$, seguido por restaurantes, con $23.70 \%$, y alojamiento, con $17.70 \%$. Al evaluar este mismo criterio respecto a los países de la AP, se encuentra que este comportamiento es muy similar. Por ejemplo, en el caso de México, el transporte también representa la mayor tasa de producción del sector turístico, con un total de $27 \%$, seguido por los servicios inmobiliarios y de alquiler, con $20 \%$, y alojamiento, con $12 \%$. Hay que destacar dos aspectos particulares: el primero de ellos es que los servicios de restaurantes no se ven representados en los tres primeros ítems en México, aun si se considera que este país, al igual que Colombia, se destaca por su alta diversidad culinaria. El otro aspecto se refiere a la distribución: en Colombia la diferencia entre las dos primeras actividades productivas del sector turístico es cercana al $20 \%$, mientras que en México dicha diferencia es tan solo del $7 \%$ (INEGI, 2011).

Colombia se ha convertido en uno de los principales destinos de muchos extranjeros. Este comportamiento está respaldado por las cifras de migración Colombia-Proexport (2012), que indican que para 2012 el total de número de personas que ingresaron al país fue de 1692 000; cifra que fue más del doble si se compara con 2004 (740 940 personas). En el análisis de Proexport se estableció que los meses que presentan mayor flujo de personas son, en este orden, diciembre, agosto y julio; igualmente, determinó que el mayor porcentaje de turistas provenía de Suramérica (44.4\%), seguido por Norteamérica (26.5\%) y Europa (18.7\%). Ahora bien, desde 2005 hasta 2012, los principales turistas que ingresan al territorio colombiano son, en este orden, estadounidenses, venezolanos, ecuatorianos, argentinos y españoles. Hay que destacar que la tasa de crecimiento de turistas chilenos para el año 2011-2012 fue de 35.8\%, la mayor de todas, seguida por los argentinos, con $18.9 \%$, y los canadienses, con $15.9 \%$.

México resulta ser un ejemplo a seguir y con el cual debemos compararnos al momento de evaluar la situación actual del sector turístico, puesto que es uno de los destinos para los turistas de todo el mundo, quienes llegan allí para desarrollar diferentes actividades, incluido trabajo y estudio. Para 2011, el total de turistas que ingresaron a dicho territorio fue cercano a 23 millones de personas, una cifra muy superior a la que reporta Colombia (14 veces mayor, aproximadamente). A diferencia del comportamiento que reporta Colombia (creciente desde el año 2005), México ha establecido una dinámica cambiante en el número de visitantes: en 2006-2007 tuvo una tendencia decreciente; en 2007-2008 crece nuevamente, y en 2008-2009 vuelve a descender por el problema generado por la aparición de una cepa del virus AH1N1 y la alerta mundial emitida por la Organización Mundial de la Salud (OMS). Una vez se superó el inconveniente, dicho comportamiento volvió a tomar una tendencia creciente.

Las cifras de turistas que ingresan a Perú (40 millones, aproximadamente) es exorbitante si se compara con Colombia ( 25 veces superior); esta cifra está asociada a los importantes paisajes que tiene este país y, sobre todo, por allí está una de las maravillas del mundo, Machu Pichu. Al igual que en Colombia, la tendencia de ingreso de turistas ha tenido un comportamiento dinámico creciente. Uno de los aspectos más relevantes y destacables es la cantidad de turistas nacionales 
que se registran, puesto que estos componen la mayor parte de la cifra reportada de 40 millones, aproximadamente. La brecha entre el número de nacionales y extranjeros que disfrutan de las actividades turísticas cada vez se amplía más. En 2004 dicha diferencia era de tan solo 13 millones, aproximadamente, mientras que para 2012 este valor alcanzó más del doble, es decir, 29 millones, aproximadamente.

Por último, según SERNATUR (2012), Chile reportó para el año 2011 una cifra de turistas cercano a los 3 millones, casi del doble generado por Colombia. Al igual que Colombia y Perú, esta tendencia desde el año 2004 ha ido al alza y tiene una tasa de crecimiento similar a la que reporta nuestro país. Ahora bien, los principales orígenes de proveniencia de dichos turistas son países suramericanos; primero está argentina, seguido por Bolivia, Brasil y Perú. Por su parte, Estados Unidos representa un porcentaje importante de visitantes, mas esta cifra ha ido decayendo desde el 2004 (momento en el cual ocupaba el tercer puesto, después de Argentina y Perú), pasando a ocupar el quinto puesto en el 2011. En ese orden de ideas, el escenario observado se convierte en una plataforma para impulsar a las PyME del sector, toda vez que por medio de los acuerdos que se formalicen en la AP se deben potenciar recursos para generar IE para echar a andar a la pequeña y mediana maquinaria de servicios turísticos de la mano de los emporios ya constituidos.

\section{Conclusiones}

El comportamiento dinámico del sector turístico colombiano ha establecido un direccionamiento creciente en todas las actividades relacionadas a este escalafón de la economía nacional, en el cual la mayor tasa de productividad se asocia directamente con el transporte, con $43.98 \%$, seguido por el de restaurante, con $23.70 \%$, y alojamiento, con $17.70 \%$.

El número de empleados del sector turismo ha tenido un comportamiento creciente durante el periodo 2006-2012, cifra que alcanzó los 140000 trabajadores, de los cuales el mayor porcentaje de ellos se asocian con la actividad de restaurantes, con $39.97 \%$, seguido por el transporte, con $27.96 \%$, y alojamiento, con $17.30 \%$.

La distribución de las actividades del sector turístico en Colombia se encuentra muy enmarcada, el mayor porcentaje de la productividad se asocia al transporte, con un valor que equivale casi a la mitad del total. Si se compara este comportamiento respecto a México, se puede decir que este último presenta una tendencia más equitativa en la participación de las actividades en la productividad final del sector.

A diferencia de Colombia, el mayor porcentaje de turistas extranjeros que ingresan a los demás países suramericanos provienen de esta misma región. Argentina se ha convertido en una de las principales naciones de origen de turistas, mas este comportamiento no es el mismo que se visualiza en Colombia, donde el mayor porcentaje proviene de Estados Unidos, seguido de Venezuela y Ecuador. Un aspecto rescatable es la participación y el incremento que tuvo el ingreso de turistas chilenos a Colombia, aumento que entre 2011 y 2012 representó un 36 \%, aproximadamente.

Colombia representa un destino predilecto para miles de turistas extranjeros y nacionales, cuestión asociada a la diversidad geográfica y climática del país. Aunque Colombia cuenta con los elementos necesarios, es destacable que el número de turistas que ingresan al territorio colombiano es muy inferior si se compara con los reportados por otros países de la Alianza del Pacifico, como México, Chile y Perú. Ante esto, es indispensable evaluar y proponer nuevos modelos políticos, económicos y organizacionales que logren potencializar el sector turístico y, ante todo, unir las diferentes PyME para que en su conjunto establezcan un sector altamente competitivo y productivo.

Colombia tiene muchos ejemplos de desarrollo a seguir si quiere aumentar su productividad y hacer más eficiente el sector turístico. Las condiciones actuales del país y el cambio de imagen 
logrado posibilita alcanzar este objetivo; pero esto debe estar guiado por la creación de políticas eficientes que regulen la prestación del servicio de este sector, en las que se establezcan realmente criterios y evaluación de la calidad. Es indispensable crear y organizar a las PyME de dicho sector, de forma que se generen lazos de intercomunicación y se den a conocer las diferentes herramientas con las que pueden contar para lograr estándares de calidad.

Colombia ha constituido un campo de acción amplio en el sector turístico, que es enfatizado y acrecentado por diferentes variables (como la diversidad geográfica y climática), lo cual resulta ser un punto a favor para que muchos extranjeros y nacionales escojan al país como destino turístico. Otro factor ha sido el cambio de imagen del país ante el mundo, debido a que la percepción de una nación violenta se ha remplazado por la de una sociedad segura, en vía de desarrollo y con políticas que aseguran la seguridad y el bienestar de los ciudadanos. Esta nueva imagen ha sido aprovechada por las PyME del sector turístico para acrecentar su productividad y generar competitividad. No obstante, el apoyo privado y público aún es insuficiente para alcanzar los estándares de calidad deseados, no solo del sector sino para asegurar del bienestar de los turistas y de los habitantes de los escenarios visitados.

\section{REFERENCIAS}

Anderson, E., y Gatignon, H. (1986). Modes of foreign entry: a transaction cost analysis and propositions. Journal of International Business Studies, XVII(3), 1-26.

Angarita, W. (2014). Gestión para el éxito de las PyMES textileras en Colombia, en el contexto del tratado de libre comercio con EE. UU. (tesis de especialización). Facultad de Ciencias Económicas, Universidad Militar Nueva Granada, Bogotá, Colombia.

Aranda, Y, y Montoya I. (2006). Principales enfoque conceptuales explicativos del proceso de internacionalización de empresas. Agronomía colombiana, 24(1), 170-181.

Aumenta turismo entre países de la Alianza del Pacífico. (14 de abril de 2015). El País. Recuperado de http://www.elpais.com.co/economia/aumenta-turismo-entre-paises-de-la-alianzadel-pacifico.html

Alianza del Pacífico. (2015). Abecé Alianza del Pacifico. Recuperado de https://alianzapacifico.net/ wp-content/uploads/2015/06/abc_AP.pdf

Banco de la República (2012). Revista mensual, marzo 2013.

Banco de Occidente (2013). La Alianza del Pacífico, una apuesta para las PyME. Boletín Mercado PyME, 14, 1. Recuperado de https:/www.bancodeoccidente.com.co/wps/wcm/connect/ banco-occidente/7103240b-1383-4c16-84d1-db58976fa2e2/boletin-14-abr-jun-2013. PDF?MOD=AJPERES, obtenido el día 18 de octubre de 2015.

Banco Mundial (2011). Doing Business 2012.Washington: Worldbank.

Bravo, A., y Rincón, A. (2013). Estudio de competitividad en el sector turismo en Colombia (tesis de pregrado). Facultad de Administración, Universidad el Rosario, Bogotá Colombia.

Cardozo, P., Chavarro, A., y Ramírez, C. (2013). La internacionalización de PyMES de alta tecnología de Bogotá. Casos de estudio. Panorama, 1(3), 43-64.

Centty, D. (2003). Informe PyME-Región Arequipa 2002. Arequipa, Perú: Nuevo mundo Investigadores \& consultores. 
clubensayos.com/Negocios. (2014). club de ensayos. Recuperado de https://www.clubensayos. $\mathrm{com} / \mathrm{Negocios} /$ ALIANZA-DEL-PACIFICO/1600508.html.

DANE. (2015) Encuesta anual de servicios. Bogotá: DANE.

Hallberg, K. (2000). A Market-Oriented Strategy For Small and Medium-Scale Enterprises (Discussion Paper n. . 40). Washington D. C.: International Finance Corporation.

Hernández, V. (2014). Estudio de factibilidad para la creación de una sucursal de la agencia de viajes turismo del Morrosquillo en la ciudad de Monteria, Córdoba (tesis de especialización). Especialización en Finanzas y Negocios Internacionales, Universidad e la Sabana, Bogotá, Colombia.

Serna, H. (ed.). 2015. Aprendizajes desde la academia sobre las pequeñas y medianas empresas. Medellín: SUMAR.

Instituto Nacional de Estadistica y Geografía. (2011). Sistema de Cuentas Nacionales de México. Cuenta satélite del turismo de México 2005-2009. Recuperado de Enhttp://www.inegi.org.mx/ prod_serv/contenidos/espanol/bvinegi/productos/derivada/satelite/turismo/2005-2009/ CSTM05-09.pdf, obtenido el día 29 de septiembre de 2015.

Johanson, J., y Wiedersheim-Paul, F. (1975). The internationalization of the firm: four Swedish cases. Journal of Management Studies, 12(3), 305-322.

León, J., y Ramírez, J. (2014). La Alianza del Pacifico. Alcances, competitividad e implicaciones para América Latina (Análisis n. ${ }^{\circ}$ 5). México: Fundación Friedrich Ebert en México.

Li, L., Li, D., y Dalgic, T. (2004). Internationalization process of small and medium-sized enterprises: Towards a hybrid model of experimental learning and planning. Management International Review, 44 (1), 93-116.

Ministerio de Comercio, Industria y Turismo. (s. f.). Mi PyMES. Portal empresarial Colombiano. Colombia: Ministerio de Industria y Turismo. Recuperado de http:/www.miPYMES.gov.co/

Ministerio de Comercio, Industria y Turismo. (2016). Informe de gestión sector comercio, industria y turismo. Bogotá: Ministerio de Comercio, Industria y Turismo.

Ministerio de Relaciones Exteriores. (s. f.) Migración Colombia. Estudios Institucionales. Colombia. Ministerio de Relaciones Exteriores. Recuperado de http://migracioncolombia.gov.co/index.php/es/?option=com_content\&view $=$ article\&id $=1437$

Modelo Upsala. (s. f.) En Wikipedia. Recuperado el 30 de mayo de 2017, de https://es.wikipedia. org/wiki/Modelo_Upsala\#cite_note-autogenerated4-4

Montoya, A., Montoya, I., y Castellanos, O. (2010). Situación de la competitividad de las Pyme en Colombia: elementos actuales y retos. Revista agronomía colombiana, 28(1), 107-117.

Moreno, M. (1981). Algunos aspectos históricos de la hotelería en Colombia. Boletín de la Sociedad Geográfica de Colombia, 35 (116). Recuperado de http://www.sogeocol.edu.co/documentos/ alg_asp_hist_hote.pdf

Ochoa, P. (2011). Las PyMES y el Comercio Exterior: ¿Por qué es necesario un plan de exportación? Buenos Aires: Universidad de Palermo, Centro de Estudios para el Desarrollo Exportador.

Ordosgoitia, E., y Ochoa, L. (2006). Caracterización de la asociatividad en las PyMES del sector turistico de Cartagena (tesis de doctorado). Programa de Administración Industrial, Facultad de Ciencias Económicas, Universidad de Cartagena, Cartagena, Colombia. 
Paternina, F. (2010). La competitividad de las PyMES ante la encrucijada de la gestión del conocimiento. Dictamen Libre, 6, 81-84.

Porter, M. E. (1990) The Competitive Advantage of Nations. Harvard Business Review (marzoabril), 73-93

Proexport. (2012). Turismo en Colombia Una Oportunidad de Inversión. Invierta en Colombia. Recuperado de http://www.proexport.com.co/

Saavedra, L. (2012). Hacia la competitividad de la Pyme Latinoamericana. Macroproyecto de investigación. Universidad Nacional Autónoma de México. Recuperado de http://www.alafec.unam. $\mathrm{mx} /$ docs/macroproyectos/competitividad_macro.pdf,

Sancho, A. (dir.). (2004). Introducción al Turismo. Madrid: Organización Mundial del Turismo. Recuperado de http://eva.universidad.edu.uy/pluginfile.php/445050/mod_resource/content/1/ introduccion $\% 20$ al $\% 20$ turismo\%2C\%20sancho\%2C\%20OMT.pdf

Sernatur. (2012) Informe barómetro de turismo al segundo trimestre 2012. Santiago de Chile: Sernatur.

Sígala, L., y Mirabal, A. (2010). Velocidad en el proceso de internacionalización de las empresas: revisión de teorias divergentes. España: Universidad de Valencia.

Silva, J. (1977). Los verdaderos dueños del país: oligarquía y monopolios en Colombia. [Bogotá]: Fondo Editorial Suramérica

Such, M., Zapata, S., Risso, W., Brida, J., y Pereyra, J. (2009). Turismo y Crecimiento Económico: Un análisis empírico de Colombia. Revista Estudios y Perspectivas, 18, 21-35.

Trujillo, M., Rodríguez, D., Guzmán, A. y Becerra, G. (2006). Perspectivas teóricas sobre la internacionalización de empresas. Bogotá: Editorial Universidad del Rosario.

Valencia, J. (1993). Cronología básica para una historia del turismo colombiano. Bogotá: Corporación Nacional de Turismo Colombia.

Zorro, C. (2009). Las pequeñas y medianas empresas (PyMES) colombianas. Bogotá: Universidad de los Andes, Programa Desarrollo Económico Local y Regional. 
